\title{
AVALIAÇÃO DA PRESENÇA DE LINFÓCITOS T NK NO SANGUE PERIFÉRICO DE PACIENTES COM LEISHMANIOSE TEGUMENTAR AMERICANA
}

Cavalcante, G. A. ${ }^{1}$, Brelaz-de-Castro, M.C. A ${ }^{1}$, Cavalcante, M. K. A ${ }^{1}$, Ribeiro,S. H. $\mathrm{P}^{1}$, Pereira, V. R.A ${ }^{2}$

${ }^{1}$ Universidade Federal de Pernambuco, Centro de Acadêmico de Vitória- CAV

2 Departamento de Imunologia, Centro de Pesquisas Aggeu Magalhães (CPqAM/FIOCRUZ), Recife, PE, Brasil;

E-mail para contato: gleyci.acavalcante@gmail.com

RESUMO - A leishmaniose tegumentar americana (LTA) é uma doença negligenciada de distribuição mundial. No Brasil, já foi diagnosticada em todos os estados. Suas manifestações clínicas variam, sendo a forma cutânea a principal forma e mais comum. A resposta imunológica desenvolvida pelo hospedeiro desempenha um importante papel na cura clínica da doença ou na sua progressão. Dessa maneira, os objetivos desse estudo foi identificar no sangue periférico de pacientes com LTA, durante o tratamento células NKt.. Os resultados desse trabalho, demostraram que células NKT, estiveram presentes em maior quantidade no sangue destes pacientes, sendo importantes na imunidade imediata à LTA.

\begin{abstract}
American tegumentary leishmaniasis (ACL) is a neglected disease of worldwide distribution. In Brazil, it has been diagnosed in all states. Its clinical manifestations vary, with the cutaneous form being the main and most common form. The immune response developed by the host plays an important role in the clinical cure of the disease or in its progression. In this way, the objectives of this study were to identify in the peripheral blood of patients with ACL, during the treatment NKt cells. The results of this work demonstrated that NKT cells were present in greater quantity in the blood of these patients, being important in immediate immunity to LTA.
\end{abstract}




\section{INTRODUÇÃO}

A leishmaniose tegumentar americana (LTA) é considerada uma doença negligenciada que acomete principalmente pessoas com menor status socioeconômico de países menos desenvolvidos, constituindo um problema de saúde pública em mais de 85 países (BRASIL, 2010; WHO, 2017).

No Brasil, está presente em todos os estados, sendo Pernambuco considerado região endêmica, onde o principal agente patogênico é L. V braziliensis (BRITO, 2012). A doença apresenta um amplo espectro de manifestações clínicas e imunológicas. Parte desses sinais clínicos varia de acordo com a resposta imune produzida pelo hospedeiro, onde destacam-se alguns grupos celulares como os linfócitos (CARVALHO, 2012).

A imunidade contra a Leishmania é mediada por uma complexa rede de parâmetros imunológicos, que incluem a resposta imune inata e adaptativa (DANTAS, 2014). Juntas, desempenham um importante papel na cura clínica da doença ou na sua progressão. A resposta imune na LTA é caracterizada principalmente pelo aumento de células $\mathrm{T} \mathrm{CD}^{+}$, onde estão bem descritos o direcionamento para um perfil de citocinas dos tipos Th1 ou Th2. No entanto, essa dicotomia (Th1xTh2) é uma simplificação da resposta imune, que é mais complexa e envolve outros subtipos de células (BRELAZ, 2012).

Além dos linfócitos TCD4+ outras populações celulares, como células NK e NKT, são conhecidas como células citotóxicas e parecem ter influência no desenvolvimento da doença ou na sua cura (KEDZIERSKI, 2014).

Portanto, através da citometria de fluxo, este trabalho pretende caracterizar células do sistema imunológico e subtipos de células T no contexto ex vivo. Neste trabalho, avaliamos a resposta de diferentes células da resposta imune de pacientes com LTA e relacionaremos esses aspectos com características clínicas dos pacientes.

\section{MATERIAIS E MÉTODOS}

\section{População do Estudo}

Participaram da pesquisa 37 pacientes procedentes de área endêmica para LTA em Pernambuco (Moreno, Jaboatão e Vitória de Santo Antão). Todos tiveram o diagnóstico

confirmado por critérios clínicos, epidemiológicos e ao menos dois testes laboratoriais considerados positivos (PCR, Citometria de Fluxo, IDRM e IFI). O grupo controle foi constituído por 10 indivíduos considerados saudáveis, residentes de área não endêmica, não-receptores de transfusão sangüínea e sem história prévia da doença. De cada indivíduo foram coletados $18 \mathrm{~mL}$ de sangue, o material coletado foi processado no laboratório de Imunogenética do Centro de Pesquisas Aggeu Magalhães (FIOCRUZ-PE), na cidade de Recife-PE. 


\section{OBTENÇÃO DE CÉLULAS MONONUCLEARES DO SANGUE PERIFÉRICO (PBMC)}

O sangue coletado foi diluído em PBS e transferido delicadamente para tubos cônicos contendo Ficoll-Hypaque. As amostras foram centrifugadas por 30 minutos a 400 x g. Realizamos a coleta da camada de PBMC, que foi transferida para um tubo cônico de $50 \mathrm{ml}$. As PBMCs foram lavadas duas vezes com $20 \mathrm{ml}$ de PBS e submetidas à nova centrifugação, a $300 \mathrm{x}$ g por 15 minutos a $20^{\circ} \mathrm{C}$. Depois do descarte do sobrenadante, o sedimento foi ressuspendido em meio de cultura RPMI 1640 (Cultilab, Campinas,SP, Brasil) suplementado com 10\% de SFB (Cultilab, Campinas,SP, Brasil) e 1\% de antibiótico $(100 \mathrm{UI} / \mathrm{ml}$ de penicilina e $100 \mu \mathrm{g} / \mathrm{ml}$ de estreptomicina; Sigma, St. Louis, MO).

As PBMCs foram cultivadas em tubos de polipropileno de $12 \mathrm{ml}$ para cultura celular. O cultivo foi realizado em meio RPMI 1640, suplementado com 10\% de soro fetal bovino (Cultilab, Campinas,SP, Brasil). As PBMCs foram cultivadas sobre 3 condições, sendo um dos tubos o controle negativo contendo apenas as células e meio RPMI, no segundo tubo as células foram estimulados com antígeno total de Leishmania $(10 \mu \mathrm{g} / \mathrm{ml})$ e para controle positivo do ensaio, foi utilizado o mitógeno fitohemaglutinina (PHA) (Cultilab) na concentração de $2,5 \mu \mathrm{g} / \mathrm{ml}$, no tubo 3. Os tubos foram mantidos em estufa à $37^{\circ} \mathrm{C} / 5 \%$ de $\mathrm{CO}_{2}$ durante 72 horas.

\section{AVALIAÇÃO CELULAR POR CITOMETRIA DE FLUXO}

Para determinação das populações de células NK e NKT, PBMCs $\left(0,5 \times 10^{6}\right.$ células/ml) foram suspensas em Tampão Fosfato-Salino (PBS) e marcadas com os anticorpos de superfície anti- CD3, CD16, CD56, por 20 minutos em Temperatura Ambiente (TA) ao abrigo da luz. Após a incubação, as células foram lavadas duas vezes com $1 \mathrm{ml}$ de PBS, seguida por centrifugação (300 x g por 10 minutos, TA). As amostras foram então ressuspendidas em $200 \mu \mathrm{L}$ de PBS e analisadas ( $>20 \mathrm{mil}$ eventos/tubo) em citômetro de fluxo (FACSCalibur- BD Bioscience) usando o software "Cell Quest Pro" (BD Bioscience) para aquisição dos dados e para análise o software FlowJo 7.6.5 (®Tree Star Inc.).

\section{ANÁLISE ESTATÍSTICA}

Para expor os resultados obtidos, realizou-se uma análise descritiva. A apresentação das variáveis mensuradas foi feita através de tabelas ou gráficos incluindo também o uso de algumas medidas descritivas. Para testar a suposição de 
normalidade e homogeneidade das variáveis envolvidas no estudo foram aplicados os testes de Shapiro-Wilk e Bartlett respectivamente.

\section{RESULTADOS E DISCUSSÃO}

No presente trabalho realizamos uma análise das células mononucleares do sangue periférico de pacientes com Leishmaniose Tegumentar antes do tratamento. Após a cultura, alguns subgrupos celulares como (NK e NKT) apresentaram percentual significativo quando comparadas ao grupo controle.

A figura 1 demonstra a comparação entre a frequência de células NKT (A) e NK (B) sem a presença de Antígeno de Leishmania braziliensis. Na figura é possível perceber que quando comparado ao grupo controle os níveis de células NK e NKT foram significativamente superiores.

Figura 1: Comparação de frequência de células NKT (A) e NK (B) em culturas de pacientes AT e grupo controle.

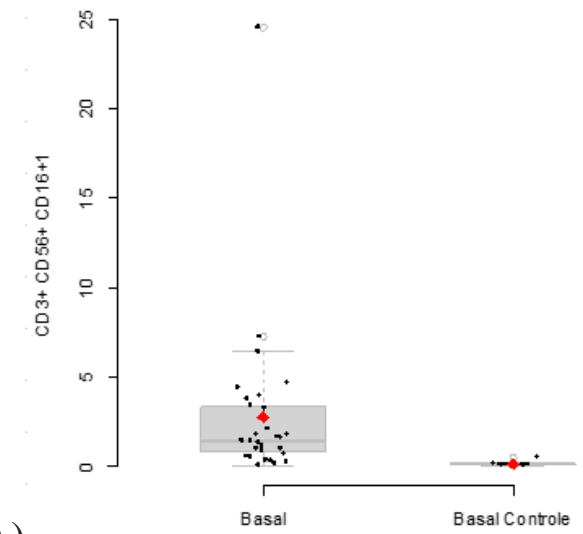

A)
B)

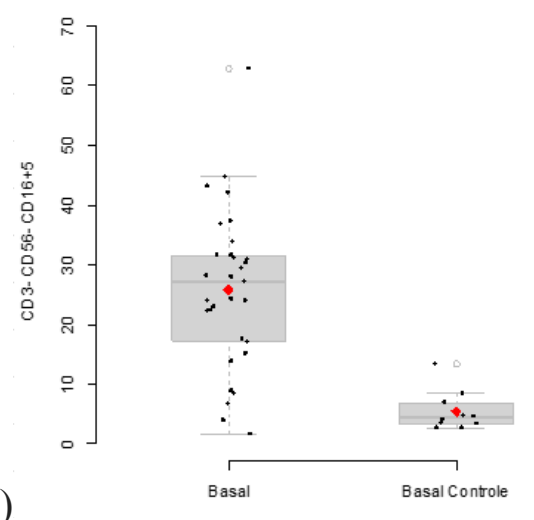

Para demonstrar a frequência de perfis celulares durante uma resposta imunológica, simulamos, in vitro, um segundo contato dessas células com o agente causador da LT, expondo essas células por 72 horas de cultura, ao antigeno total de Leishmania braziliensis.

Nesse ensaio células NK também apresentaram percentual aumentado quando comparadas ao grupo controle. Os valores estão representados graficamente abaixo.

$\mathrm{Na}$ figura 2, comparamos a frequência de células NKT em cultura celular pós estimulação com antígeno total de Leishmania brasiliensis. O gráfico demonstra o aumento significativo dessa população celular na cultura das células mononucleares, coletadas no sangue periférico, de pacientes com doença ativa quando comparado ao grupo controle. 
Figura 2-Comparação de frequência de células NKT, em 72 horas de cultura de células com antígeno total de Leishmania braziliensis.

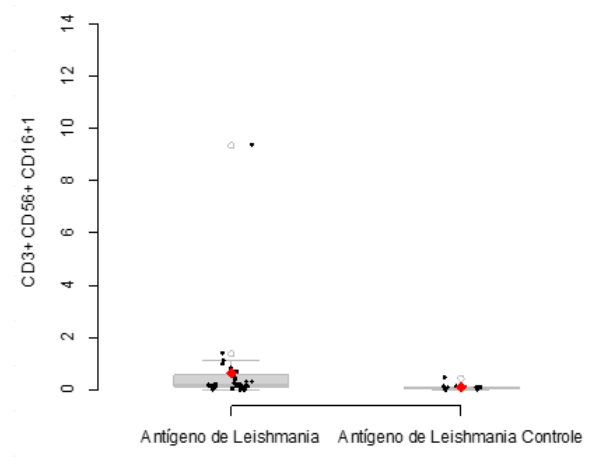

Por ser considerado um problema de saúde pública, uma vacina capaz de promover uma resposta imunológica eficaz, que controle a infecção por LTA seria um modelo ideal. Contudo, para atingirmos progressos no desenvolvimento dessas estratégias, é necessário um maior entendimento da resposta imunológica associada à cura e à proteção dessa doença (MACHADO, 2014).

Neste trabalho pudemos avaliar as células do sistema imune (NK, NKT) A partir do desenho experimental identificamos a frequência dessas células citotóxicas presentes na infecção por Leishmania spp.

Pouco se sabe ainda sobre a participação das células NK e NKT na resposta imune frente à Leishmaniose em pacientes (RAPHAEL, 2015). Neste trabalho, maiores percentuais de células NK e NKT foram observados no grupo de pacientes com a doença ativa (AT) quando comparado ao grupo controle. Estudos in vitro associam a frequência aumentada de células NK e NKT, no sangue periférico de pacientes com LTA, não só a capacidade citotóxica dessas células, mas também à produção de citocinas como IFN- $\gamma \mathrm{e}$ TNF, que contribuem para o desenvolvimento de uma resposta Th1 e à ativação de macrófagos (RUGANI, 2015).

Estudos sobre a distribuição das células NKT na LTA são extremamente escassos, tendo sido pouco documentado na literatura se estas células alteram seus percentuais com a doença, com o tratamento antimonial ou com a cura clínica. Alguns desses trabalhos mostraram que, pelo menos, em modelos murinos de LTA, essas células parecem bloquear a expansão do parasita e também impulsionar a resposta imune específica e protetora. 


\section{CONCLUSÃO}

Em nosso trabalho percebemos que esse grupo celular está presente no sangue periférico de pacientes com LTA, sendo rapidamente ativado e mostrando-se expansivo frente à um segundo contato com o antígeno de Leishmania braziliensis. Nossa investigação teve como foco a participação de células citotóxicas na resposta imune frente à leishmaniose tegumentar americana. Essas descobertas nos estimulam a considerar a citotoxicidade como um fenômeno que deve ser melhor explorado, não apenas por células citotóxicas clássicas (NK e CD8 +), mas também células NKT. Ainda existem muitas lacunas a serem preenchidas a respeito dos mecanismos imunológicos desenvolvidos na leishmaniose. Estudos profundos que garantam compreender esses mecanismos garantirão no futuro a projeção de novas estratégias terapêuticas de vacinas eficazes e de alternativas imunoterapeuticas para a Leishmaniose humana.

\section{REFERÊNCIAS}

BRASIL. Ministério da Saúde. Secretaria de Vigilância em Saúde. Manual de Vigilância da Leishmaniose Tegumentar Americana. 2 ed atual. Brasília: Editora do Ministério da Saúde, 2010. 180 p.

BRELAZ, M. C. A. et al. Antigenic fractions of Leishmania (Viannia) braziliensis: the immune response characterization of patients at the initial phase of disease. Parasite Immunology, Oxford, v. 34, n. 4, p. 236-9, 2012

BRITO, M. E. F. et al. Occupationally acquired american cutaneous leishmaniasis. Case Reports in Dermatological Medicine, Nova Iorque, v. 2012, p. 1-4, 2012.

CARVALHO, L. P. et al. Protective and pathologic immune responses in human tegumentar leishmaniasis. Frontiers in Immunology, Lausanne, v. 3, p. 301, 2012.

DANTAS, M. L.; et al. Comparative analysis of the tissue inflammatory response in human cutaneous and disseminated leishmaniasis. Mem. Inst. Oswaldo Cruz, v. 109, n. 2, p. 202- 209, Apr. 2014

KEDZIERSKI, L.; EVANS, K. J. Immune responses during cutaneous and visceral leishmaniasis. Parasitology, n. 141, p. 1544-1562, 2014.

MACHADO, M. M. Análise de diferentes cepas de Leishmania (Leishmania) amazonensis e Leishmania (Viannia) braziliensis quanto a infectividade/virulência e perfil de citocinas e quimiocinas produzidas por macrófagos murinos infectados. 2014. 136 f. Dissertação (Mestrado em Programa de Pós-Graduação Biologia Parasitária) - Instituto Oswaldo Cruz, Rio de Janeiro, 2014. 
RAPHAEL, I.; et al. T cell subsets and their signature cytokines in autoimmune and inflammatory diseases. Elsevier, n. 74, p. 5-17, 2015.

RUGANI, J. M. N. Estudo da Variabilidade Genética de Leishmania (Viannia) braziliensis em Minas Gerais, Brasil. 2015. 107 f. Dissertação (Programa de Pós-Graduação em Ciências da Saúde) - Centro de Pesquisas René Rachou, Belo Horizonte, 2015.

WORLD HEALTH ORGANIZATION - WHO. Disponível em: http://www.who.int/gho/neglected_diseases/leishmaniasis/en/. Acesso em: 06 de Janeiro de 2017.

\section{AGRADECIMENTOS}

Aos órgãos fomentadores dessa pesquisa, FACEPE e CNPQ e ao Instituto de Pesquisa Aggeu Magalhães por disponibilizar sua estrutura e equipamentos. 